
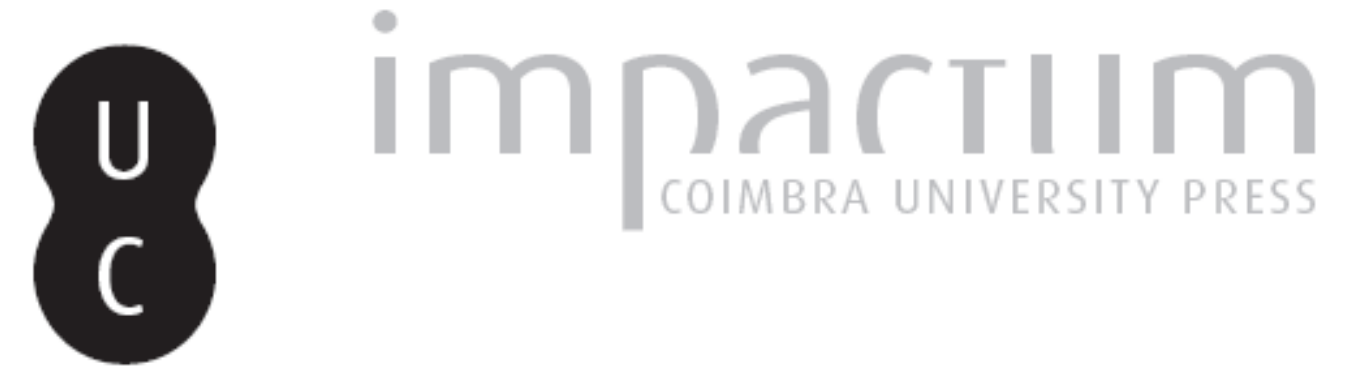

Educação de infância e política educativa em Portugal no último quartel do século XX

Autor(es): $\quad$ Ferreira, António Gomes; Mota, Luís

Publicado por: Imprensa da Universidade de Coimbra

URL persistente:

URI:http://hdl.handle.net/10316.2/36827

DOI:

DOI:http://dx.doi.org/10.14195/1647-8622_14_2

Accessed : $\quad$ 26-Apr-2023 09:47:33

A navegação consulta e descarregamento dos títulos inseridos nas Bibliotecas Digitais UC Digitalis, UC Pombalina e UC Impactum, pressupõem a aceitação plena e sem reservas dos Termos e Condições de Uso destas Bibliotecas Digitais, disponíveis em https://digitalis.uc.pt/pt-pt/termos.

Conforme exposto nos referidos Termos e Condições de Uso, o descarregamento de títulos de acesso restrito requer uma licença válida de autorização devendo o utilizador aceder ao(s) documento(s) a partir de um endereço de IP da instituição detentora da supramencionada licença.

Ao utilizador é apenas permitido o descarregamento para uso pessoal, pelo que o emprego do(s) título(s) descarregado(s) para outro fim, designadamente comercial, carece de autorização do respetivo autor ou editor da obra.

Na medida em que todas as obras da UC Digitalis se encontram protegidas pelo Código do Direito de Autor e Direitos Conexos e demais legislação aplicável, toda a cópia, parcial ou total, deste documento, nos casos em que é legalmente admitida, deverá conter ou fazer-se acompanhar por este aviso.

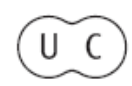




\section{educação e democracia}

ESTUD OSD OSÉCULO

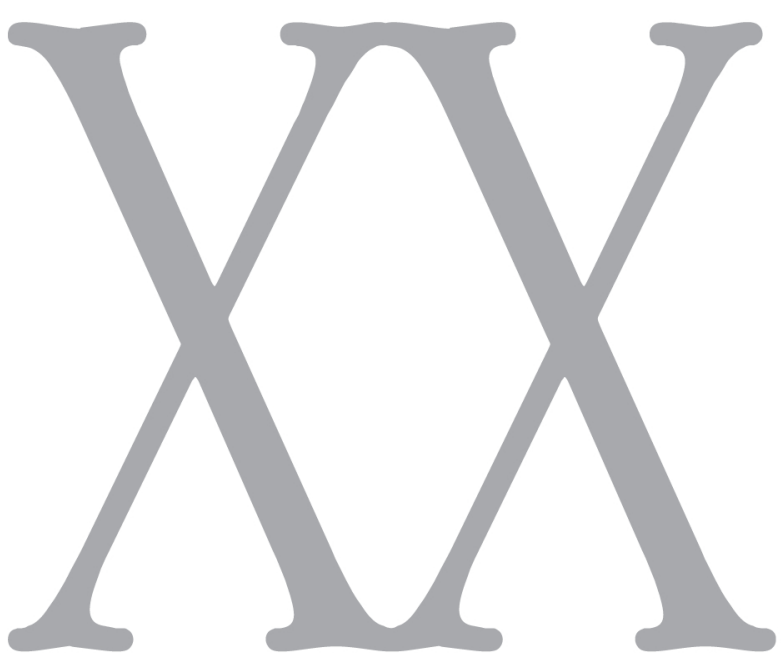

número 14 • 2014

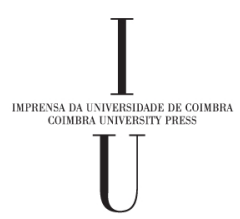




\section{EDUCAÇÃO DE INFÂNCIA E POLÍTICA EDUCATIVA EM PORTUGAL NO ÚLTIMO QUARTEL DO SÉCULO XX}

António Gomes Ferreira

Luís Mota 
António Gomes Ferreira, Doutor em Ciências da Educação pela Universidade de Coimbra. Professor Associado e subdiretor da Faculdade de Psicologia e de Ciências da Educação da Universidade de Coimbra. Coordenador científico do GRUPOEDE do CEIS20. E-mail: antonio@fpce.uc.pt

Luís Mota, Doutor em História da Cultura pela Faculdade de Letras da Universidade de Coimbra. Professor Adjunto do Instituto Politécnico de Coimbra, Escola Superior de Educação. Investigador do CEIS20. E-mail: mudamseostempos@gmail.com 


\section{O movimento social popular e o desenvolvimento da educação de infância}

Dos acontecimentos após 25 de abril de 1974 resultou o colapso do "Estado fascista" ${ }^{1}$. No ano e meio que se lhe seguiu o Estado constituiu-se numa plataforma múltipla de lutas sociais e políticas sem que nenhum bloco social de poder alcançasse o seu controlo, contribuindo para uma certa paralisia administrativa. A tentativa de fazer alinhar o Estado com as propostas do movimento social popular parece ter estado na génese, pelo menos nalguns setores, de um "Estado dual"2.

O Ministério da Educação foi colhido em plena reestruturação ${ }^{3}$, num país onde o Estado tinha (e mantém) um papel central na política educativa ${ }^{4}$ e num momento em que à educação era conferida centralidade no debate sobre o modelo social de desenvolvimento. A sua atuaçáo e a dos seus responsáveis foi condicionada pela atividade de estruturas sindicais e pelas organizaçóes partidárias estudantis, nas escolas e no próprio aparelho de Estado ${ }^{5}$. Nos estabelecimentos de ensino, onde emergiram uma agenda reivindicativa ${ }^{6}$ e formas de controlo participativo ${ }^{7}$, professores e alunos (e funcionários) agiram face a um poder central que, como que paralisado, se revelava incapaz de antecipar ou mesmo acompanhar o sentido dos acontecimentos.

Da conjuntura política resultou um mandato para o sistema educativo que se expressava na democratizaçáo do sucesso e no combate às desigualdades sociais ${ }^{8}$, constituindo um período de revalorização da Educação Pré-Escolar em Portugal ${ }^{9}$. Logo em Maio de 1974, ainda que de forma vaga, o programa do I governo provisório sublinhava a intenção de ampliar a cobertura de educação pré-escolar como estratégia de consagração do princípio de igualdade de oportunidades ${ }^{10}$.

\footnotetext{
${ }^{1}$ SANTOS, Boaventura Sousa - O Estado e a Sociedade em Portugal (1974-1988). 3a ed. Porto: Ediçóes Afrontamento, 2000. 266 p. ISBN 972-36-0241-5.

${ }^{2}$ Idem, ibidem.

${ }^{3}$ Cf. AMBRÓSIO, Teresa - O sistema educativo: ruptura, desestabilização e desafios europeus. In REIS, António - Portugal Contemporâneo. Volume III. Lisboa: Alfa/Selecçốes Reader's Digest, 1996. ISBN 972-609-159-4, p. 665-674.

${ }^{4}$ Cf. STOER, Stephen R. - "O Estado e as Políticas Educativas: uma proposta de mandato renovado para a Escola Democrática”. Revista Crítica de Ciências Sociais. Coimbra: CES. ISSN 0254-1106. N. 41 (1994), p. 3-33.

${ }^{5}$ Cf. AMBRÓSIO, Teresa - O sistema educativo..., p. 665-674.

${ }^{6}$ Cf. GRÁCIO, Rui - "Problemas e perspetivas do ensino em Portugal. Um debate com professores". In GRÁCIO, Rui - Obra Completa. Volume III. Lisboa: Fundação Calouste Gulbenkian, 1996. ISBN 972-310659-0, p. 273-316.

${ }^{7}$ Cf. STOER, Stephen R. - Educação e mudança social em Portugal, 1970-1980, uma década de transição. Porto: Ediçōes Afrontamento, 1986. 293 p.

${ }^{8}$ Cf. STOER, Stephen R.; STOLEROFF, Alan D.; CORREIA, José Alberto - "O Novo Vocacionalismo na Política Educativa em Portugal e a Reconstruçâo da Lógica da Acumulaçâo". Revista Crítica de Ciências Sociais. Coimbra: CES. ISSN 0254-1106. N.o 29 (1990), p. 11-53.

${ }^{9}$ Cf. VILARINHO, Maria Emília - Politicas de Educação Pré-Escolar em Portugal (1977-1997). Lisboa: Instituto de Inovação Educacional, 2000. 267 p. ISBN 972-8353-95-2

${ }^{10}$ Cf. PORTUGAL. Decreto-Lei n. ${ }^{\circ}$ 203/74, de 15 de Maio. Diário de Governo. I Série. N.o 113, de 15 de maio de 1974, p. 626.
} 
No debate e ação ideológica confrontaram-se duas vias de condução do processo revolucionário, a da dinâmica de bases e a da instrumentalizaçấo ${ }^{11}$. A dinâmica de bases baseava-se na ação mobilizadora da intervenção dos atores na vida de cada escola e na construção local do processo democrático, defendendo a democracia direta, apresentando-se como um poder democraticamente legitimado, alternativo e limitador de uma intervenção mais uniformizadora do Ministério da Educação. Logo após o 25 de Abril, esta conceção está presente na ocupação de escolas, nos saneamentos dos reitores, de professores e funcionários comprometidos com o Estado Novo, nas comissóes de gestão que irromperam nos liceus, criando formas de controlo participativo. A via da instrumentalização, seguidora de uma lógica centralizadora fundada num modelo ideológico definido, associado a experiências e lógicas de regimes de um socialismo centralizador (estatista), pugnou por uma dinâmica do centro para a periferia, a partir, precisamente, da instrumentalização de dimensóes do saber escolar, de princípios ideológicos e de técnicas de organização da sociedade, afirmando-se, nomeadamente, em domínios onde a legitimidade democrática não caucionava o movimento social popular. Respaldada na intervençáo homogeneizante do Estado compaginada com alguma permeabilidade aos circunstancialismos locais, encetou uma reforma do ensino normal primário.

O movimento social popular, sustentáculo da via de dinâmica de bases, através da iniciativa de comissóes de moradores, de organizaçóes de base, juntas de freguesia e paróquias, contribui para a expansão de contextos informais de educação pré-escolar, criando creches e jardins-de-infância, em resposta à procura social da guarda de crianças, marcadas pela precariedade das instalaçóes, a insuficiência dos recursos e a ausência de recursos humanos qualificados. As condiçóes de existência e as dificuldades económicas estiveram na origem de solicitaçóes de apoio e financiamento aos ministérios dos Assuntos Sociais - em instituiçóes para crianças dos 0 aos 6 anos - e da Educaçáo e Investigação Científica - serviços para crianças dos 3 aos $6 \operatorname{anos}^{12}$.

A via da instrumentalizaçâo que se identificava com açóes coordenadas e de iniciativa do Ministério da Educação, consubstanciadas no novo modelo de escola constante do designado "Plano Melo Antunes"13, operacionalizadas, nomeadamente, nas modificaçóes propostas para as Escolas do Magistério Primário, foi parca no domínio das realizaçóes, no que à educação pré-escolar, diz respeito. No ano letivo de 1975-1976, ensaiou-se a criação do curso do magistério infantil, nas referidas escolas, de entre as que para isso tivessem condiçóes, passando a ministrar os dois cursos do magistério, infantil e primário, com a

\footnotetext{
${ }^{11}$ Cf. FERREIRA, António Gomes; MOTA, Luís - “A formação de professores do ensino primário durante a crise revolucionária (1974-1976) ". HENRIQUES, H. - Educação e formação de professores: história(s) e memória(s). Portalegre: Instituto Politécnico/Escola Superior de Educação, 2013. ISBN 978-989-96701-9-8, p. 79-83.

${ }^{12}$ Cf. VILARINHO, Maria Emília - Políticas ..., pp. 109-110.

${ }^{13}$ PORTUGAL. Governo Provisório da República Portuguesa - Programa de Política Económica e Social. Lisboa: Imprensa Nacional - Casa da Moeda, 1975. 184 p.
} 
duração de três anos, sendo o $1^{\circ}$ ano de frequência comum. Esta opção foi suspensa logo no ano letivo seguinte aquando do início da normalização $0^{14}$.

Na verdade, no domínio da educação pré-escolar, os governos provisórios, traduziram mais preocupação do que ação ${ }^{15}$. Nas "Linhas de acção do Ministério da Educação e Cultura”, do conselho de ministros de 16 de Agosto de 1974, ministério à data tutelado por Vitorino Magalhães Godinho, propóe-se "preparar jardineiras para os jardins-deinfância" ${ }^{16}$, em Portugal, através da criação de nova escola de formação, ou no estrangeiro, com recurso à concessão de bolsas. Simultaneamente, quando discutia os caminhos do futuro, o historiador ministro, destacava a necessidade de criação de uma "rede nacional de jardins de infância" 17 ciente de que é desde "tenra idade que se jogam as possibilidades de igualizar as oportunidades" ${ }^{\prime 1}$. Na mesma linha e direcionando o olhar para as mesmas vertentes, no "Plano Melo Antunes", para além da abertura do curso do magistério infantil, manifestava-se a intenção de adotar as "medidas destinadas à criação de um sistema oficial de educação pré-escolar" ${ }^{19}$, através da promoção e desenvolvimento de uma rede escolar, quer criando um quadro de educadores de infância.

Indícios, no plano da política educativa e das declarações de intençóes, que denunciavam preocupaçóes com as fragilidades do setor em Portugal, nomeadamente com as suas consequências ao nível do desenvolvimento mas, muito especialmente, ao nível da construção da cidade democrática e do exercício da cidadania. De resto, um relatório sobre a educação em Portugal, produzido no quadro da $\mathrm{UNESCO}^{20}$, em 1975, encarregar-se-ia de desocultar tal realidade, sublinhando a precariedade da educação infantil bem como colocava a nu os desfasamentos entre o tempo curto da retórica e da ação política e o tempo longo da educaçáo e do ensino. Na verdade o relatório previa que só se alcançaria a generalização da educação pré-escolar, em face da cobertura nacional e do ratio entre crianças e educadores de infância, em quatro décadas. A tomada de consciência do atraso e, quiçá, o confronto com tal avaliação externa, conduziram o governo à elaboração e apresentação de um projeto-lei, de 14 de maio de 1975, com o objetivo de criar a rede pública de educação pré-escolar. As dificuldades experimentadas ao nível dos recursos humanos - a inexistência de educadoras e as soluçóes então propostas -

\footnotetext{
${ }^{14}$ Cf. MOTA, Luís - A Escola do Magistério Primário de Coimbra. Entre Ideologia, Memória e História. Tomo I. Coimbra, 2006. Dissertaçáo de doutoramento. 832 p.

${ }^{15}$ Cf. VASCONCELOS, Teresa - Das Casa de Asilo ao Projecto de Cidadania. Políticas de Expansão da Educação de Infância em Portugal. Porto: Ediçōes ASA, 2005. 62 p. ISBN 9724141276

${ }^{16}$ GODINHO, Vitorino Magalhães - A educação num Portugal em mudança. Lisboa: Edições Cosmos, 1975. p. 33.

${ }^{17}$ GODINHO, Vitorino Magalhães - A educação..., p. 39.

${ }^{18}$ Idem, ibidem.

${ }^{19}$ PORTUGAL. Governo Provisório da República Portuguesa - Programa de Política Económica e Social. Lisboa: Imprensa Nacional - Casa da Moeda, 1975. 184 p.

${ }^{20}$ Cf. UNESCO - Para uma política de educação em Portugal. Lisboa: Livros Horizonte, 1982. 73 p.
} 
e o problema das instalaçóes, levaram à rejeição da proposta ministerial pelas próprias profissionais, temendo uma massificação sem assegurar previamente a sua qualidade ${ }^{21}$.

A preocupação com o alargamento da cobertura da educação pré-escolar conduziu, posteriormente, à organização de grupos de trabalho, no âmbito dos ministérios da Educação e dos Assuntos Sociais, e de comissóes interministeriais (Ministério dos Assuntos Sociais, Ministério da Educação e representantes dos sindicatos) para contribuir para a definição de uma política para a proteção à maternidade e à infância $\mathrm{e}$ para assegurar uma integração dos serviços responsáveis pelo setor. Uma das comissóes, criada por proposta da Direção-Geral do Ensino Básico, em Junho de 1975, definiu a educação pré-escolar como o "conjunto das acções de educação e protecção infantil que visam a promoçáo do bem-estar e do desenvolvimento das crianças" 22 dos 0 aos 6 anos e, simultaneamente, aconselhava que os serviços fossem integrados num único organismo que assegurasse o "planeamento e a execução das acçóes"23.

A ideia de integração seria objeto de resolução do conselho de ministros, em fevereiro de 1976, criando para o efeito a Comissáo Interministerial para a Educaçáo e Proteção Infantil (CIEPI), a quem estava cometida a tarefa de contribuir para a definição de uma política de educação e proteção infantil, reorganizar os serviços no sentido da integração e preparar a criação de um organismo que assegurasse "a rede nacional de serviços de Educação e Protecção Infantil"24.

Não se passaria da manifestação de vontades, confrontando-se, desde logo, com a histórica multiplicidade de serviços sob tutela do Ministério da Educação e da dos Assuntos Sociais. A diversidade de tutela encerrava diferenças concetuais. As instituiçóes superintendidas pelo Ministério dos Assuntos Sociais centravam a sua organização em torno da guarda e da proteção de crianças, estoutras tuteladas pelo Ministério da Educação priorizavam objetivos educacionais. Objetivos que se traduziam em preocupaçóes e práticas organizacionais diferenciadas e materializadas em dimensóes como o horário de atendimento, na estrutura física do edifício e no ratio entre pessoal docente e não docente, entre outros aspetos. Uma característica incontornável da educação pré-escolar, entre nós, nas décadas seguintes. Diferenciação que se associava à heterogeneidade da população infantil e à segregação social comprovada em sede de relatório da Fundação Calouste Gulbenkian, publicado em $1975^{25}$. Aí se explicitava que as crianças de meios familiares com nível socioeconómico elevado frequentavam os jardins-de-infância privados e com fins lucrativos, enquanto as instituiçóes dependentes da assistência social acolhiam crianças de meios sociais pobres ou carenciados.

${ }^{21}$ Cf. CARDONA, Maria João - Para a História da Educação de Infância em Portugal. O discurso oficial (1834-1990). Porto: Porto Editora, 1997. 173 p. ISBN 972-0-34453-9.

${ }^{22}$ GOMES, Joaquim Ferreira - A Educação Infantil em Portugal. Coimbra: Livraria Almedina, 1977. p. 121.

${ }^{23}$ Idem, ibidem.

${ }^{24}$ Idem, ibidem.

${ }^{25}$ FUNDAÇÃO CALOUSTE GULBENKIAN - Plano de relatório do inquérito a jardins-de-infância (1975). Citado por VILARINHO, Maria Emília - Políticas..., p. 112. 
A democratização do acesso e a igualdade de oportunidades passavam pela adoção de uma política de expansão da educaçáo pré-escolar. Contudo, o desenvolvimento da educação pré-escolar pública, durante este período, ficou a dever-se ao exercício de cidadania e à participaçáo democrática, o mesmo será dizer, na capacidade e no poder dos cidadáos e das cidadâs de pressionarem o governo no sentido da resolução dos seus problemas ${ }^{26}$.

A Constituição de $1976^{27}$, materializando as preocupaçóes com a equidade, cometia ao Estado a incumbência de criar um sistema público de educação pré-escolar. Aparentemente, faltou Estado para cumprir a Constituição e a expansão da educação pré-escolar tardou.

\section{Diferentes perceçóes do papel da educação de infância}

O período que decorre desde o fim da crise revolucionária, em 1976, até à publicaçáo da lei de bases do sistema educativo, dez anos mais tarde, fica precisamente marcado pela convivência de duas conceçôes de educação de infância, facto que de resto se prolonga pela década seguinte. A educação pré-escolar era percebida como complementar da família ou, em alternativa, via acentuarem-lhe as suas funçóes educativas. Estoutra acabaria por prevalecer.

Foi durante a normalização que ocorreu a reintegração da educação de infância no sistema educativo português e consequentemente teve lugar a génese da criação do sistema público de educaçáo pré-escolar. O legislador atribuiu às instituiçóes de educação pré-escolar, sob alçada do Ministério da Educação, apenas as crianças dos 3 aos 6 anos. A lei definia como objetivos a promoção do "desenvolvimento harmónico da criança” ${ }^{28}$ e a correção das desigualdades socioculturais de acesso ao sistema escolar ${ }^{29}$.

Uma perspetiva que foi objeto de crítica em relatório dos serviços do Ministério da Educaçãa ${ }^{30}$. Ao promover a separação entre instituiçôes para as crianças da $1^{\text {a }}$ infância e outras para as de idades compreendidas entre os 3 e os 6 anos de idade, a lei acabou por acentuar a separação, já referenciada, entre os serviços do Ministério da Educação e os da Segurança Social.

A publicação, em 1979, dos Estatutos dos Jardins-de-Infância ${ }^{31}$, regulamentando a atividade dos jardins-de-infância da rede pública, centrava os objetivos da educação pré-

${ }^{26}$ Cf. VASCONCELOS, Teresa - Das Casa de Asilo..., p. 34.

${ }^{27}$ Cf. PORTUGAL - Constituição da República Portuguesa. Coimbra: Atlântida Editora, 1976. 103 p.; PORTUGAL - "Constituiçăo de 2 de abril de 1976". MIRANDA, Jorge - As Constituiçóes Portuguesas de 1822 ao texto actual da Constituição. $5^{a}$ ed. Lisboa: Livraria Petrony - Editores, 2004. ISBN 972-685-104-1. p. 281-368.

${ }^{28}$ Portugal. Lei n. ${ }^{\circ}$ 5/77, de 1 de fevereiro de 1977. Diário da República. I Série. N.o 26, de 1 de fevereiro de 1977.

${ }^{29}$ Idem, ibidem.

${ }^{30}$ Cf. CARDONA, Maria João - Para a História..., p. 87.

${ }^{31}$ PORTUGAL. Decreto-Lei no 542, de 31 de dezembro de 1979. Diário da República. I Série. N.o 300, 120 Suplemento, de 31 de dezembro de 1979. 
escolar no desenvolvimento socio-afetivo das crianças, reforçava a especificidade da educação de infância em relação à escola e, por outro lado, as normas de funcionamento estabelecidas, de que era exemplo a definição de um horário reduzido, em nome das necessidades educativas das crianças, acentuavam o afastamento em relaçáo às preocupações do Ministério dos Assuntos Sociais ${ }^{32}$.

O Estado compaginou o papel de regulador com o de mobilizador, congregando iniciativas várias para a criação e funcionamento de jardins-de-infância. Em meados da década de oitenta assistiu-se uma progressiva alteração do papel do Estado, esbatendo-se a sua intervenção direta na criação de estruturas pré-escolares. A rede pública continuou a ser insuficiente, mesmo insignificante no que se refere à oferta para crianças entre 0 e os 3 anos de idade. A sua expansão concretizou-se no meio rural, respeitando as áreas de intervenção e os interesses da rede particular e cooperativa, incorporando a solidariedade familiar de apoio às crianças e o horário de atendimento semelhante ao do $1^{\circ}$ ciclo e, simultaneamente, as salas de aulas do $1^{\circ}$ ciclo, vazias, por força da desertificação populacional.

Esta complementaridade das zonas de intervenção, entre o público e o privado, serviu o interesse de ambos os sectores, orçamental e expansionista, respetivamente. Esta estratégia permitiu ao Estado refrear o investimento estatal e, paralelamente, reduzir o impacto da pressão social da procura. Contudo, debilitou o princípio da igualdade de oportunidades enfraquecendo a garantia do direito das crianças a uma educação préescolar pública e gratuita, tal como estava consagrado na Constituiçáo da República ${ }^{33}$.

O sentido do crescimento da rede pública permite-nos constatar a presença do que Boaventura Sousa Santos definiu como a sociedade civil secundária ${ }^{34}$, uma vez que o Estado utilizou o seu papel de regulador para garantir mercado para o capital privado bem como para o "fortalecimento de agentes sociais privados orientados para outros fins que não a obtenção de lucros mas igualmente envolvidos na produção de bens e serviços" 35 . Num tempo de juridificação da educação ${ }^{36}$, o Estado criava juridicamente os parceiros sociais e formalizava o reconhecimento e o modo de intervenção da sociedade civil na educação, sendo disso exemplo, a promulgação, em 1979, do Estatuto das Instituiçóes Particulares de Solidariedade Social, abrindo uma janela de oportunidade para as instituiçóes de solidariedade social organizarem e desenvolverem atividades para a infância (dos 0 aos 6 anos de idade).

No domínio da formação de educadoras de infância e enquanto grupo profissional, criaram-se, em 1977, cursos de formação de educadores de infância ${ }^{37}$, nas Escolas

${ }^{32}$ Cf. CARDONA, Maria João - Para a História....

${ }^{33}$ Cf. VASCONCELOS, Teresa - Das Casa de Asilo..., p. 33-35.

${ }^{34}$ Cf. SANTOS, Boaventura de Sousa - O Estado..., p. 221-223.

${ }^{35}$ Idem, ibidem.

${ }^{36}$ Cf. CORREIA, José Alberto - As ideologias educativas em Portugal nos últimos 25 anos. Porto: Ediçōes ASA, 2000. ISBN 972-41-2316-2. p. 10-12.

${ }^{37}$ Cf. PORTUGAL. Lei 6/77 de 1 de Fevereiro de 1977. Diário da República. I Série. N.o 26, de 1 de Fevereiro de 1977. 
Normais de Educação de Infância (ENEI), cujos estatutos ${ }^{38}$ foram publicados dois anos mais tarde. Os estatutos, que designam como escolas normais de educadores de infância, os estabelecimentos de ensino de Coimbra, Viana do Castelo, Viseu e Guarda, preveem, ainda, a criação das Escolas Superiores de Educação (ESE) que a curto prazo seriam responsáveis pela formação de educadores.

As transformaçóes operadas na sociedade com consequências no sistema educativo e nas condições de trabalho dos profissionais da educação pré-escolar, nomeadamente, a maior abertura dos estabelecimentos de ensino à comunidade, a situaçáo de trabalho em pequenas aldeias, em realidades bem diferentes de outras em que tinham realizado a sua formação, e em situação de isolamento, entre outros, levaram a Divisão de Educação PréEscolar do Ministério da Educação (DEPE) a desenvolver, desde 1978, açôes de formação para educadores, no âmbito da pedagogia, da psicologia e da sociologia. Já na década de oitenta, a Divisão publicou um conjunto de documentos de apoio ao trabalho desenvolvido nos jardins-de-infância da rede pública. Em Outubro de 1986 deu à estampa um texto que "explicita algumas orientaçôes relativas a aspetos administrativos e pedagógicos" ${ }^{39}$ para a organização do trabalho a desenvolver na rede pública ${ }^{40}$.

Marco fundamental e incontornável na história e na afirmação das educadoras de infância foi a criação, em 1981, da Associação de Profissionais de Educação de Infância (APEI), tendo estado na sua génese a preocupação com a necessidade de "dar uma maior visibilidade aos educadores como profissionais" ${ }^{41}$.

Em 1986, ano de início de funcionamento dos cursos das escolas superiores de educação (ESE) e de publicação da lei de bases do sistema educativo, a cobertura institucional para crianças, dos 0 aos 3 anos de idade, era da ordem dos 5,6\% e, para a $2^{\text {a }}$ infância, chegava aos $35,6 \%$, o que, mesmo reconhecendo alguma falta de fiabilidade nestes números, colocava Portugal, no momento em que adere à Comunidade Económica Europeia, na cauda da Europa em termos de taxas de cobertura ao nível da educação pré-escolar. No que se refere a recursos humanos, existiam 10308 educadores de infância no país, dos quais, 57,9\% formadas em escolas privadas ${ }^{42}$.

\section{Sob o signo da Lei de Bases e da Reforma do Sistema Educativo}

Passemos por cerca de uma década que, na quase totalidade, se traduz num tempo de retração das políticas de desenvolvimento da rede pública de jardins-de-infância ${ }^{43}$.

\footnotetext{
${ }^{38}$ Cf. PORTUGAL. Decreto-Lei 519-R2/79 de 29 de dezembro de 1979. Diário da República. I Série. N.o 299, de 29 de dezembro de 1979.

${ }^{39}$ CARDONA, Maria João - Para a História..., p. 95.

${ }^{40}$ Idem, ibidem, pp. 84-85, 95.

${ }^{41}$ CARDONA, Maria João - Educação de Infância. Formação e Desenvolvimento Profissional. Lisboa: Ediçôes Cosmos, 2006. ISBN 978-972-762-27-57. p. 165.

${ }^{42}$ Cf. CARDONA, Maria João - Para a História..., p. 94, 97.

${ }^{43}$ Cf. VILARINHO, Maria Emília - Politicas..., p. 186.
} 
Momento marcado pela publicaçáo da lei de bases do sistema educativo e pela implementação da Reforma Educativa. A involução na expansão da rede pública poderá atribuir-se à ideologia da modernização e à conceção das funçóes reconhecidas à educação pré-escolar, consagradas, nomeadamente, na Lei de Bases do Sistema Educativo ${ }^{44}$.

A partir do segundo lustro da década de oitenta, o campo retórico da educação emergiu marcado pela ideologia da modernização e a definição económica da educação. Os discursos educativos tiveram como centro de preocupaçóes a eficácia, os padróes de qualidade e a formaçáo para o trabalho, adquirindo visibilidade o binómio educação/modernização do tecido produtivo. $\mathrm{O}$ mundo empresarial obteve um significado particular na reorganização do campo educativo e, simultaneamente, as ideias de mercado e livre escolha alcandoraram-se a ideal de funcionamento dos sistemas educativos.

O campo semântico da educação foi empresarializado, modo de "legitimação da empresarialização da intervenção do Estado" ${ }^{5}$ e das "normas de qualidade do interesse público na educação" ${ }^{46}$ serem definidas no campo empresarial. A lógica consumista apropriou-se da escola, transformando os utentes do serviço público em clientes. O discurso da modernização reelaborou problemáticas, casos da permeabilização da educação a contextos locais e da igualdade de oportunidades, subordinando a educação à modernizaçáo económica, naturalizando uma certa definição das relaçôes entre formação e trabalho.

A modernização do país e as novas condiçóes do sistema económico e produtivo condicionaram as opçóes de política educativa. Nesta ambiência o discurso da Reforma Educativa deu prioridade à qualificação dos recursos humanos e à diversificação da oferta ao nível da pós-escolaridade obrigatória. As referências discursivas à educação préescolar e sua expansão inseriram-se no domínio de uma mera construção retórica ${ }^{47}$.

Ao nível da Lei n.o 46/86, Eurico Lemos Pires destacava, no seu comentário, duas coordenadas que ajudam à compreensão da retração. Por um lado, a educação pré-escolar era considerada facultativa, com especificidade própria, autónoma, o que lhe conferiu uma natureza não preparatória da educação escolar e, por outro, a perspetiva da sua articulação com o meio familiar, conferindo à família um papel essencial no processo educativo, sendo estoutra vertente, considerada uma das especificidades da educação pré-escolar ${ }^{48}$. A segunda coordenada prendia-se com a progressiva redefiniçáo do papel do Estado como promotor, através de uma releitura do articulado da Lei de Bases - "Incumbe ao Estado assegurar a existência de uma rede de educação pré-escolar" ${ }^{49}$-, à luz da ideologia da modernização, considerando que "assegurar a existência da rede" não determinava que o

\footnotetext{
${ }^{44}$ PORTUGAL. Lei 46/86, de 14 de outubro. Diário da República. I Série. N. ${ }^{\circ} 237$, de 14 de outubro de 1986.

${ }^{45}$ CORREIA, José Alberto - As ideologias..., p. 15.

${ }^{46}$ Idem, ibidem.

${ }^{47}$ Cf. VILARINHO, Maria Emília - Politicas..., p. 186.

${ }^{48}$ Cf. Portugal. Lei de Bases do Sistema Educativo. Apresentação e Comentários de Eurico Lemos Pires. Porto: Ediçôes ASA, 1987. 144 p.

${ }^{49}$ Idem, ibidem.
} 
Estado a promovesse diretamente, posicionamento que permitia desvalorizar o papel do Estado como promotor, reforçando-o como mobilizador e regulador ${ }^{50}$. Esta orientação do Estado conduziu, por um lado, ao aparecimento de jardins-de-infância sem cobertura legal para a sua existência e, por outro, à estagnação da rede pública ${ }^{51}$.

Muito embora os relatórios da Comissão de Reforma do Sistema Educativo e da Comissão de Análise e Expansão da Rede de Educação Pré-Escolar (CAER) denunciassem as deficiências da oferta e as assimetrias regionais de cobertura da rede, o Estado aguardou pela iniciativa privada. A CAER no seu Plano de Desenvolvimento da Educaçáo PréEscolar elencava seis aspetos fundamentais na ação a conduzir pelo Estado, dos quais definiu como prioritários, a expansão da rede pré-escolar, de modo que permitisse alcançar uma cobertura da ordem dos $75 \%$ em 1997, a promoção da qualidade da oferta através da articulação interministérios e a melhoria do acompanhamento técnico e a inspeção das instituiçóes. Este documento tornou mais visível a defesa da alteração do papel do Estado ${ }^{52}$.

Foi necessário aguardar por 1995 para que o Estado assumisse algumas das recomendaçóes, com a publicaçáo do decreto-lei n. ${ }^{\circ}$ 173/95 que definiu o "regime de atribuição pelo Ministério da Educação, de apoios financeiros à criação e manutenção de estabelecimentos de educação pré-escolar" ${ }^{33}$. A ação do Estado foi no sentido da liberalização, criando condiçóes para o aparecimento de um mercado educacional ${ }^{54}$. $\mathrm{Na}$ linha da ideologia de modernização e da definição económica da educação, ainda que retome a expansão, a política do ministério da Educaçáo tutelado por Manuela Ferreira Leite, náo garantiu o direito a uma educação pré-escolar pública e gratuita e colocou em causa os princípios da democratização de ensino e da igualdade de oportunidades educativas ${ }^{55}$.

Esta leitura só tem acolhimento se olharmos estes operadores ideológicos na perspetiva da ideologia democrática, onde a igualdade de oportunidades se compagina com a ação uniformizadora do Estado no sentido de garantir igualdade de acesso aos saberes transmitidos pela escola. Contudo, a importação deste operador ideológico pela ideologia da modernização, referencia a igualdade de oportunidades ao respeito pelos interesses individuais dos seus clientes e não à democratização ${ }^{56}$. A partir de 1995 , parecendo de algum modo coincidir com a mudança da equipa governativa, retomavase a fase de expansão, com a iniciativa do legislador, ao criar 791 salas de jardins-deinfância congeladas desde 1988 e uma vasta produção legislativa que culminou com a publicação da lei-quadro da educação pré-escolar.

\footnotetext{
${ }^{50}$ Idem, ibidem.

${ }^{51}$ VILARINHO, Maria Emília - Políticas..., p. 186.

${ }^{52}$ Cf. VASCONCELOS, Teresa - Das Casas..., p. 38-39.

${ }^{53}$ VILARINHO, Maria Emília - Políticas..., p. 187.

${ }^{54}$ Cf. DALE, Roger - "A promoção do mercado educacional e a polarização da educação". Educação, Sociedade \& Culturas. Porto: CIIE/Edições Afrontamento. ISSN 0872-7643. N. 2 (1992) p. 109-139.

${ }^{55}$ Cf. VILARINHO, Maria Emília - Politicas..., p. 187.

${ }^{56}$ Cf. CORREIA, José Alberto - As ideologias..., p. 16.
} 
No que se refere ao papel do Estado, devemos assinalar a continuidade da política neoliberal, valorizando o papel de regulador e de garantia, assegurando o exercício do direito à livre escolha das condiçóes de cumprimento da escolaridade, por parte dos pais, os clientes, e da pluralidade da oferta, através do exercício do direito de participaçáo da sociedade civil, que tantas vezes se confundia com o mundo empresarial.

O papel do Estado seria mesmo clarificado em sede de relatório do Departamento de Educação Básica (1996). Ao Estado, explicitava-se, caberia uma atuação mobilizadora no sentido de assegurar para todas as crianças o acesso à educaçáo préescolar. A sua função seria estratégica, muito especialmente compaginando o desenvolvimento de um sistema de apoio à iniciativa privada com medidas de incentivo à administração pública autárquica e o estimular à generalização duma rede de oferta de serviços de atendimento à criança. Acrescentava-se, no referido relatório, que não competia ao Estado assegurar diretamente uma rede de serviços mas, ao invés, a sua responsabilidade seria a de promover um conjunto de açôes de suporte, nas áreas financeira, de apoio e controlo técnico bem como de orientaçáo e supervisáo educativa ${ }^{57}$.

\section{A educação pré-escolar como primeira etapa da educação básica}

Como já sublinhámos, desde 1988, aquando da criação do "Programa Interministerial de Promoção do Sucesso Educativo” (PIPSE), e até ao final do primeiro lustro da década de 90 que não foram criados jardins-de-infância da rede pública. A educação de infância, ainda que desde 1973 fosse considerada um nível do sistema educativo e um serviço educativo de interesse público, viu o seu papel manter-se ambíguo ${ }^{58}$.

O Conselho Nacional de Educação, com parecer de 1994, deu visibilidade política à problemática da educação pré-escolar incidindo a sua análise, nomeadamente, sobre a ausência de crescimento da rede pública e as assimetrias de funcionamento e estatuto das instituiçôes, bem como produzindo um conjunto de recomendaçóes de cariz político-educativo ${ }^{59}$. A produção legislativa do ano seguinte, a que já aludimos, não só não acompanhou as principais recomendaçôes do Conselho como deixou por resolver a ambiguidade que envolvia a educação de infância ${ }^{60}$.

${ }^{57}$ Cf. MINISTÉRIO DA EDUCAÇÃO/DEPARTAMENTO DE EDUCAÇÃO BÁSICA - Educação Pré-Escolar em Portugal. Lisboa: Departamento de Educação Básica, 1996. 62 p. ISBN 972-742-071-0.

${ }^{58}$ Cf. FORMOSINHO, Joâo - "Comentário à Lei N. ${ }^{\circ} 5 / 97$ de 10 de Fevereiro. Lei Quadro da Educaçāo Pré-Escolar”. MINISTÉRIO DA EDUCAÇÃO/DEPARTAMENTO DE EDUCAÇÃO BÁSICA - Educação Pré-Escolar. Legislação. Lisboa: Departamento de Educação Básica/Núcleo de Educação PréEscolar, 1997. ISBN 972-742-091-5. P. 29-43.

${ }^{59}$ Cf. CONSELHO NACIONAL DE EDUCAÇÃO - "Parecer n.o 1/94 do Conselho Nacional de Educação sobre a educaçáo pré-escolar em Portugal”. PORTUGAL - Diário da República. II Série. N.o 135. 14 de fevereiro de 1994. p. 5800 (14) - 5800 (28).

${ }^{60}$ Cf. CONSELHO NACIONAL DE EDUCAÇÃO - "A expansão da educaçãoo pré-escolar - análise de um projeto de decreto-lei do Ministério da Educação. Parecer n. ${ }^{\circ}$ 2/95". PORTUGAL - Diário da República. II Série. N.o 183. 9 de agosto de 1994. p. 9337 - 9341. 
Com a mudança governamental, decorrente da tomada de posse do XIII Governo Constitucional, em 1995, a educação foi afirmada como uma "paixão" e uma prioridade, propondo-se o governo ultrapassar o atraso português no espaço de uma geração. Foi mesmo criado um conselho de ministros específico para a coordenação entre a educação, a cultura, a ciência e tecnologia, a juventude e o trabalho e formação profissional ${ }^{61}$. Priorização que, muito especialmente, incluiu a educação pré-escolar ${ }^{62}$.

De facto, foi elaborada uma estratégia para o desenvolvimento e expansão da educação pré-escolar ${ }^{63}$ que esteve na base do Plano de Expansão e Desenvolvimento da Educação Pré-Escolar em Portugal ${ }^{64}$ e na criação do Gabinete para a Expansão e Desenvolvimento da Educaçáo Pré-Escolar a quem foi cometida a tarefa de dar exequibilidade ao Plano.

No quadro deste conjunto de medidas o legislador publicou a Lei-Quadro para a Educação Pré-Escolar ${ }^{65}$ que definiu como a primeira etapa da educação básica percebida como base de sustentação para a aprendizagem ao longo da vida - e, simultaneamente, como um serviço social básico. Um serviço educativo indissociável de uma componente social, sendo que é precisamente a sua essência pedagógica que a diferenciam de outros serviços de apoio à criança ${ }^{66}$.

É neste enquadramento que se compreendem as orientaçóes políticas para a expansão da rede e a articulação entre ministérios, da Educação e da Solidariedade, como meio de garantir a componente educativa e a social. É criado, para o efeito, o Gabinete Interministerial para a Expansão e Desenvolvimento da Educação PréEscolar $^{67}$, constituído por representantes dos dois ministérios e presidido pela Diretora da Educação Básica e que tinha, como objetivos, a conceção das linhas de ação e a criação de incentivos ao lançamento de programas de inovação, de formação e de pesquisa. De salientar o papel desempenhado na celebração de protocolos com as instituições percebidas como fundamentais para garantir a expansão da rede nacional de educação pré-escolar, na melhoria da qualidade pedagógica e social da oferta e no assegurar da articulação entre ministérios.

${ }^{61}$ Cf. BENAVENTE, Ana - "Portugal, 1995-2001: reflexôes sobre democratização e qualidade na educação básica”. Revista IberoAmericana de Educación [em linha]. N.o 27 (2001). [Consult. 26 de julho de 2014]. Disponível em WWW: <U. R. L.: http://www.rieoei.org/rie27.htm>. ISSN: 1022-6508

${ }^{62}$ Cf. MINISTÉRIO DA EDUCAÇÃO. Educação Pré-escolar...

${ }^{63}$ FORMOSINHO, J.; VASCONCELOS, T. - Relatório estratégico para a expansão e desenvolvimento da Educação Pré-Escolar. Lisboa: Ministério da Educação, 1996. Citado por VASCONCELOS, Teresa - Das casas de asilo..., p. 40.

${ }^{64}$ Cf. MINISTÉRIO DA EDUCAÇÃO. Plano para a expansão e desenvolvimento da educação pré-escolar. Lisboa: Ministério da Educação, 1996. Citado por VASCONCELOS, Teresa - Das casas de asilo..., p. 40-41.

${ }^{65}$ Cf. PORTUGAL. Lei 5/97, de 10 de fevereiro. Diário da República. Série I - A. N.o 34, de 10 de fevereiro de 1997.

${ }^{66}$ Cf. FORMOSINHO, João - “Comentário à Lei N.o 5/97..., p. 31.

${ }^{67}$ Cf. PORTUGAL. Despacho 186/ME/MSSS/MEPAT/96, de 3 de setembro. Diário da República. II Série. N.o 204, de 3 de setembro de 1996. 
A lei-quadro consagrou o conceito de tutela pedagógica única como competência do Ministério da Educação. Instrumento considerado adequado para garantir que a oferta educativa assegurava serviços no plano educativo e social. Concomitantemente, definia orientaçóes gerais enquadrando a educação pré-escolar, ao nível pedagógico e técnico, entendidas como possibilidades múltiplas e assentes na responsabilização dos intervenientes ${ }^{68}$.

A tutela pedagógica única deveria ser co-construída exigindo, para o efeito, uma dinâmica coletiva e interativa implicando os envolvidos no plano nacional e local, bem como público e privado. Para o efeito a lei determina a criação de uma rede nacional de educação pré-escolar, agregando público e privado, nomeadamente, a rede solidária.

Do ponto de vista educativo, ao ser considerada como a primeira etapa da educação básica compaginada com o reconhecimento dos efeitos positivos, da educação préescolar, no sucesso educativo das crianças e na promoção da igualdade de oportunidades colocava na ordem do dia, necessariamente, a importância da sua articulação com o $1^{\circ}$ ciclo do ensino básico, sublinhando a importância de articular as mudanças no préescolar com aqueloutras a introduzir no $1^{\circ}$ ciclo do ensino básico.

É neste quadro de intervenção que, após dois anos de consulta pública, são publicadas as Orientaçôes Curriculares para a Educação Pré-Escolar ${ }^{69}$. A sua publicação foi acompanhada da divulgação de um documento orientador que explicitava as linhas de orientação curricular $^{70}$. As Orientaçóes para além dos aspetos relacionados com a organizaçáo geral do trabalho definem, ainda, três áreas de conteúdo - formação pessoal e social, expressão e comunicação (domínios da expressão motora, dramática, plástica e musical, linguagem oral e abordagem à escrita e, finalmente, da matemática), e do conhecimento do mundo. A expressão de área de conteúdo consubstancia uma nova perspetiva em relação à forma tradicional de conceber a educação de infância, apresentando "uma concepção mais alargada, que para além de valorizar a componente desenvolvimentista salienta também uma componente cultural e a aquisiçáo de conhecimentos"71.

Neste período, o Estado acentua o papel de regulador que se traduzia na produção legislativa, na prestação de apoio técnico e pedagógico, na adequação do sistema de inspeção e de supervisão no sentido de operacionalizar a avaliação pedagógica e do sistema e na monitoragem permanente do sistema de forma a permitir-lhe o desempenho do papel compensatório - dedicando especial atenção às desigualdades sociais e às assimetrias regionais ${ }^{72}$.

\footnotetext{
${ }^{68}$ Cf. PORTUGAL. Lei 5/97, de 10 de fevereiro. Diário da República. Série I - A. N. ${ }^{\circ}$ 34, de 10 de fevereiro de 1997, p. 35.

${ }^{69}$ Cf. PORTUGAL. Despacho 5220/SEEI/97, de 10 de julho. Diário da República. II Série. N.o 178, de 4 de agosto de 1996.

${ }^{70}$ Cf. CARDONA, Maria João - Educaçäo de Infância. Formação e Desenvolvimento Profissional. Chamusca: Ediçôes Cosmos, 2006. ISBN 972-762-275-5. p. 139.

${ }^{71}$ Idem, ibidem, pp. 139-140.

${ }^{72}$ Cf. VASCONCELOS, Teresa - Das Casas..., p. 44-45.
} 
Em jeito de balanço ou como epílogo, destaquemos que durante o segundo lustro da década de 90 se registou uma expansão da rede nacional de educação pré-escolar de $54,5 \%$ para 71,6\%, representando uma taxa de cobertura, para crianças de 5 anos de idade, da ordem dos $84,2 \%, 72,4 \%$ para 4 anos de idade e, finalmente, para os 3 anos, atingiram-se os 58,3\%. Garantiu-se a articulação interministerial, entre os ministérios da Educaçáo e o da Solidariedade e Segurança Social, bem como se celebraram protocolos e/ou contratos de desenvolvimento com autarquias, instituiçóes particulares de solidariedade social e instituiçóes do ensino particular e cooperativo. Em 1997, estabeleceu-se como habilitação mínima para o exercício da educação de infância, a licenciatura $^{73}$. Finalmente, efetuaram-se construçóes e adaptaçóes de edifícios para a educação pré-escolar ${ }^{74}$.

Em publicação que integra dois relatórios, um elaborado por equipa portuguesa a partir de uma grelha de análise proposta pela Organizaçáo para a Cooperação e Desenvolvimento Económico (OCDE) e um outro com reflexóes, sugestóes e críticas de técnicos da OCDE, relevava-se o esforço (político, económico e social), realizado por Portugal, no período subsequente a 1995, ao nível do bem-estar das crianças e da significativa expansão dos serviços prestados à infância, num curto espaço de tempo. No relatório, contudo, não deixavam de se elencar um conjunto de aspetos sobre os quais se considerava importante refletir e agir. Genericamente podemos agrupar os assuntos em quatro grandes áreas temáticas, como sejam a articulação entre a decisão e ação política, a monitorização e avaliação do sistema, o estatuto, condiçóes de serviço e formação de educadores e educadoras de infância e na investigação sobre a qualidade da oferta e a obtenção de estatísticas mais fidedignas ${ }^{75}$.

$\mathrm{Na}$ verdade, também em sede de relatório, o Conselho Nacional da Educação reconheceu o esforço realizado por Portugal, na década de 90, do século XX, ainda assim, insuficiente para que a cobertura de Educação Pré-Escolar em Portugal se possa comparar com os seus congéneres europeus ${ }^{76}$.

Mais recentemente, num estudo desenvolvido por Maria Emília Vilarinho centrado na análise da implementação da componente de apoio à família em jardins-de-infância públicos, a autora chama a atenção para as crescentes influências dos processos de globalização e transnacionalização com repercussóes nas políticas educativas e nos direitos das crianças à educação. $\mathrm{Na}$ sua apreciação conclusiva, embora destaque o grande esforço desenvolvido para aumentar as taxas de pré-escolarização deixa claro que,

\footnotetext{
${ }^{73}$ PORTUGAL. Lei n. ${ }^{1}$ 115/97. Diário da República - I Série A. N.o 217, de 19 de setembro de 1997, p. 5082-5083.

${ }^{74}$ Cf. VASCONCELOS, Teresa - Das Casas..., p. 41-42.

${ }^{75}$ Cf. MINISTÉRIO DA EDUCAÇÃO. A Educação Pré-Escolar e os Cuidados para a Infância em Portugal. Lisboa: Ministério da Educação/Departamento da Educação Básica, 2000. 146 p. ISBN 972-742-133-4.

${ }^{76}$ Cf. CONSELHO NACIONAL DE EDUCAÇÃO - Educação de infância em Portugal: Situação e Contextos numa Perspectiva de Promoção de Equidade e Combate à Exclusão. Lisboa: Conselho Nacional de Educação/Fundação Calouste Gulbenkian, 2003. 289 p. ISBN 972-8360-22-3
} 
apesar disso, os objetivos estabelecidos em 1997 para a universalização da educação préescolar ainda não tinham sido atingidos ${ }^{77}$.

\section{Notas finais}

A primeira nota a considerar reporta-se ao papel do Estado e a sua ligação à importância da rede escolar e às questóes da democratização de acesso e igualdade de oportunidades. Com o 25 de abril a política de expansão da educação pré-escolar é percebida como pré-requisito para a democratizaçáo do acesso e a igualdade de oportunidades. Num primeiro momento, o Estado cedeu o passo ao Movimento Social Popular e depois de politicamente consagrado faltou Estado para fazer cumprir a Constituição. O Estado desvalorizou, progressiva e de forma acentuada a partir da década de oitenta, a função de promotor de uma rede pública de educação pré-escolar e acentuou o seu papel de mobilizador e de regulador. Ele procurou assegurar a existência de uma oferta plural de educação pré-escolar compaginada com o exercício do direito de participação da sociedade civil. Contudo, embora tenha garantido, a espaços, a expansão da rede escolar, não cuidou do direito a uma educação pré-escolar pública e gratuita e colocou em causa os princípios da democratizaçáo de ensino e da igualdade de oportunidades educativas. Numa leitura que referencia a igualdade de oportunidades ao respeito pelos interesses individuais, a preocupação do Estado centrou-se em assegurar o exercício do direito à livre escolha das condiçóes de cumprimento da escolaridade por parte dos clientes. De algum modo e considerando os diferentes momentos históricos e as nuances discursivas, o papel do Estado regulador parece ter ganho consenso no discurso e na ação política governativa no último quartel do século XX.

Merece uma referência a leitura de separação entre a problemática social, traduzida no cuidado e proteção das crianças, e a educativa, naturalmente focalizada na educação das crianças, com a correspondente dicotomia na tutela ministerial. No período de 1974-1976 esse quadro não se alterou, visível, nomeadamente, ao nível das solicitaçôes de financiamento no âmbito do movimento social popular. Contudo, retoricamente aconselhava-se a integração para assegurar unidade na ação (1975). Criou-se, inclusivamente, uma comissão interministerial (1976) cometendo-se-lhe a tarefa de definir uma política de educação e proteção infantil. Ao invés, o Estatuto dos Jardins-de-Infância (1979) encarregou-se, até pelas normas de funcionamento estabelecidas para a rede

${ }^{77}$ Cf. VILARINHO, Emília - "Políticas educativas para a infância: o caso da educação pré-escolar em Portugal (1995-2010)”. DORNELLES, Leni Vieira; FERNANDES, Natália Ed. - Políticas sociológicas e educacionais em estudos da criança: as marcas das dialogicidades luso-brasileiras. [em linha] Braga: CIEC/Universidade do Minho, s. d., p. 365-384 [Consultado a 22 de julho de 2014]. Disponível em WWW: <URL: http:/www.ciec-uminho.org/ documentos/ebooks/2307/pdfs/ 6\%20Inf\%C3\%A2ncias\%20e\%20Pol\%C3\%ADticas\%20Educacionas/Pol\%C3\% ADticas\%20Educativas\%20para\%20a\%20inf\%C3\%A2ncia.pdf>; VILARINHO, Maria Emília - O Estado e o Terceiro Setor na Construção de Políticas Educativas para a Infância em Portugal: o caso da Educação Pré-Escolar (19952010). Braga. Universidade do Minho, 2011. 
pública, de acentuar clivagens em relação às orientaçóes do ministério que tutelava as questóes sociais. Foi necessário aguardar pelo último lustro da década de 90 do século passado para se agir efetivamente em termos de aproximação e articulação, com benefício para a garantia das componentes educativa e social, nomeadamente com a criação de um gabinete interministerial e a determinação de uma tutela pedagógica única implicando os atores em presença. A questão náo ficou definitivamente resolvida, já que em sede de relatório a OCDE (2000) recoloca-a como vertente a merecer um olhar atento.

Não cabia, nem coube no nosso trabalho qualquer referência ao Estado Novo e às suas conceçôes sobre a educação da infância, o que nos ajudaria a compreender o atraso português, no que à educação de infância respeita, na entrada para o último quartel do século XX. Apesar dos renovados discursos dos sucessivos governos provisórios de criação de uma rede de educação pré-escolar e de formação de quadros qualificados, não existiu a ação equivalente que passasse das palavras aos atos. Na verdade, logo em 1975, por via de um relatório, a UNESCO se encarregou de caracterizar a verdadeira dimensão do atraso português, assinalando quarenta anos para a sua superação. A avaliar pelos estudos que mobilizámos, estamos em crer que necessitaremos de mais anos para anular o referido atraso. De sublinhar, com alguma veemência, que o atraso não pode ser atribuído (exclusivamente) a questóes materiais ou a acontecimentos pretéritos. De facto, como pensamos ter enfatizado, nos últimos vinte cinco anos do século $\mathrm{XX}$, o lugar e o papel que se atribuiu à educação pré-escolar - onde, por vezes, náo será despiciente uma releitura das representaçôes sobre a temática em Portugal ao longo do século XX -, contribuiu para um investimento noutros setores educativos. A justificação pode encontrar-se nos imperativos de modernização e como eram acolhidos entre nós, bem como na desvalorização (e ambiguidade) do lugar da educação pré-escolar no sistema educativo. O paradigma só se alterou definitivamente no último lustro do século XX, com a educação pré-escolar a ser considerada primeira etapa da educação básica, base de sustentaçáo para a aprendizagem ao longo da vida.

A formação de educadores e educadoras de infância acompanhou a evolução da formação dos professores e das professoras do ensino primário ao longo do último quartel do século XX. Desde os primeiros governos provisórios, o discurso político compaginou sempre as preocupaçóes com a criação e desenvolvimento da rede de educação pré-escolar com a formação de profissionais qualificados. Desde o primeiro ensaio, enquadrado pelas "experiências pedagógicas" nas escolas do magistério primário, em 1975, a formação inicial de educadores e educadoras de infância foi-se consolidando, primeiro, com as escolas normais de educação de infância e, com a criação do ensino superior politécnico, nas escolas superiores de educação. A evolução institucional compaginou-se com um crescente aumento do período de formação e de grau académico que encerra com a determinação da licenciatura como habilitaçáo mínima para o exercício da educação de infância. Esta etapa traduz o reconhecimento da necessidade de igual período de formação e grau académico para todo o corpo docente da educação pré-escolar e ensinos básico e secundário. Momento que não pode deixar de 
ser interpretado, também ele, como um reconhecimento da importância da educação pré-escolar. Paralelamente, o próprio Ministério da Educação, através da Divisão de Educação Pré-Escolar, criou um programa de formação contínua e um outro editorial. 